solution will secure the future of India in world affairs or internally which attempts to ignore or override these fundamental differences of culture and tradition.

\section{New Government Technical School at Takoradi}

THE opening of the new Government Technical School at Takoradi introduces a further development of this type of education in the Gold Coast. Increased demand for technical instruction necessitated the removal of the school from Accra, where the accommodation proved to be inadequate. Moreover, the new site is more favourably placed in relation to the industrialized area of the Gold Coast. The new Technical School occupies a prominent site overlooking the sea and Takoradi Harbour, and the more important buildings include a long single-story workshop with blacksmith's shop at the rear, a threestory administration block containing classrooms, laboratories, drawing offices, assembly hall and dining-room and a dormitory block capable of housing one hundred students. The workshop is in two sections, one for practical work in mechanical engineering and the other for practical woodworking. Both sections are fitted with modern electrically driven machinery such as lathes, power drills, shapers, etc., in addition to the usual benches for manual work.

Other buildings include the European housemaster's bungalow, two blocks of quarters for eight African masters, a block of six labourers' quarters, a large timber-drying store, petrol store and garage. The buildings are grouped around a five-acre sports ground. In addition, there are facilities for safe seabathing and boating. The buildings are fitted with electric clocks controlled by a master clock; most of the classrooms and the assembly hall are wired for the reception of wireless re-diffusion from the Sekondi broadcasting station; and there is complete waterborne sanitation. Candidates for admission must be in possession of a Standard VII Certificate or its equivalent. Present students include boys from Nigeria, Dahomey and all parts of the Gold Coast. Among entries for next year are three boys from Sierra Leone. The total cost of the scheme has been approximately $£ 37,500$, which includes approach roads, laying out of grounds, etc., the area covered by the school and grounds being some thirty acres.

\section{Fishery Research in the Italian Empire}

THE rapidity of scientific development in the new Italian Empire is well illustrated by the subject of aquatic biology. Only three years have elapsed since the conquest was complete, and yet the recently formed Direzione Superiore Affari Colonizzazione $e$ Lavoro has already set up an Ufficio Idrobiologia e Pesca at Addis Ababa, under the direction of Prof. P. Parenzan, and a considerable amount of preliminary research has taken place on the inland waters of the former Ethiopia. These are described in the first number of a new official journal entitled Bollettino di Idrobiologia, Caccia e Pesca. It is a well-appointed publication, containing papers on fish, their impor- tance in the food of native peoples, parasites and pathology, and accounts of other aspects of the biology of fresh waters, including the fish-eating birds and Mollusca.

Meanwhile, in the past half century, the vastly greater areas of lakes and rivers in British eastern Africa, containing correspondingly greater resources, have been subjected only to spasmodic and short-term scientific examinations, and most of these have resulted from the initiative of individual scientific workers or institutions not immediately concerned with colonial development. Perhaps the new policy in colonial research and development which has recently been announced by the Colonial Secretary may lead, after the War, to the inclusion of fisheries in both the sea and fresh waters in a widely planned scheme of research.

\section{Paratypical Forms in Man's Line of Descent}

IN a discussion, and incidentally a criticism on certain points, of the announcement of the discovery in Java of an upper jaw attributed to Pithecanthropus erectas (see NATuRE, 144, 926; 1939), Prof. G. Montandon brings forward a suggestion which he argues would resolve certain of the difficulties inherent in apparent discrepancies in the evidence (Rev. Scientifique, 78, 1; 1940), and maintains that had Dr. von Koenigswald included the palatal view of the jaw in the figures accompanying the announcement of the find, it would have been evident that Pithecanthropus stands outside the Hominidæ. Prof. Montandon says that its shape is that of the $\mathrm{U}$ characteristic of the anthropoid jaw and not that of the horseshoe form found in man. Further, the simian diastema separating the incisors and eanines is present here, though never found in man. At the same time, this disparity does not warrant classification of the jaw as that of a gibbon or other form of anthropoid. For, as Prof. Montandon goes on to point out, the teeth and especially the canines are not Simian but those of a Hominid. Comparison of the jaw with that of Sinanthropus definitely places the latter as belonging to a more advanced type and within the Hominid group.

The discussion becomes even more suggestive when Prof. Montandon passes on to consider the significance of Dr. Broom's recent discoveries in South Africa. Here in Paranthropus is a form which shows a like combination of incompatible characters. In eranial form Paranthropus is more Simian than Hominid, but at the same time in form of jaw and teeth it is the reverse. The jaw shows the horseshoe form, the absence of diastema, and a humanoid dentition. Prof. Montandon therefore goes on to ask the question, pertinent on his interpretation of the evidence, whether there may not be another form in which, as with Pithecanthropus, the cranium approaches the human more nearly than do the Paranthropoids of South Africa, but less human than them in respect of the dental arch. His further suggestion of a whole series of paratypes of wide distribution raises an interesting and wide question which at present rather hangs in the air. 